\title{
PEMBUATAN SERBUK KARBON AKTIF DARI LIMBAH BAMBU SEBAGAI PENYANGGA KATALIS LOGAM DALAM SINTESIS BIOFUEL SECARA FISCHER-TROPSCH
}

\author{
Endah Kusuma Rastini ${ }^{1}$, Jimmy ${ }^{1}$, Wahyu Panji Asmoro² \\ ${ }^{1}$ Jurusan Teknik Kimia, Fakultas Teknologi Industri, Institut Teknologi Nasional Malang \\ 2Jurusan Teknik Mesin, Fakultas Teknologi Industri, Institut Teknologi Nasional Malang \\ Jln. Bendungan Sigura-gura No 2 Malang 65145, Telp. 0341-551431 \\ e-mail : endahkr@gmail.com
}

\begin{abstract}
Fischer-Tropsch synthesis is an alternative route for conversion of biomass into liquid fuels which is quite promising because biofuel product has characteristics identical to fossil fuels. Biomass is converted to synthesis gas $\left(\mathrm{CO}\right.$ and $\left.\mathrm{H}_{2}\right)$ by polymerization into long chain hydrocarbons (waxes) and subsequently cut into cracking processes resulting in short chain hydrocarbons $\left(C_{5}-C_{12}\right)$ which are biofuels. Use of activated carbon as a support can produce biofuel directly. This study aims at characterizing activated carbon powder as a metal catalysts support in Fischer-Tropsch synthesis and utilize bamboo waste as activated carbon soursce. The activated carbon from bamboo was produced by an activation combination of Carbonization $\mathrm{H}_{3} \mathrm{PO}_{4}(A)$, Carbonization- $\mathrm{H}_{3} \mathrm{PO}_{4}-\mathrm{Steam}(\mathrm{B})$. Bamboo was size-reduced, dried and carbonated at $500^{\circ} \mathrm{C}$ with nitrogen stream in carbonization reactor, powdered, then activated with $85 \% \mathrm{H}_{3} \mathrm{PO}_{4}$ and washed to neutral $\mathrm{pH}$. After drying, the sample was functionalized with $65 \% \mathrm{HNO}_{3}$, neutralized, dried and calcined at $700^{\circ} \mathrm{C}$. The crystal structure of activated carbon was analyzed using XRD. Activated carbons of various activation sequences had identical XRD profiles and had shown specific spectra for activated carbon. The resulting activated carbon corresponds to the crystal structure based on the diffraction angle of XRD analysis. Activated carbon initiated by steam and then treated with phosphoric acid (B) showed better results in the oxygen functional groups formation. The spectrum of the functional groups of alcohols, phenols, carbonyls, carboxylates appeared with considerable intensity compared to the activation treatment without steam. This suggests that a combination of physical activation (steam) and chemical activation (phosphoric acid) increased the formation of oxygen functional groups compared with the nitric acid functionalization only.
\end{abstract}

Keywords: bamboo waste, powder activated carbon, catalyst support

ABSTRAK

Sintesis Fischer-Tropsch merupakan rute alternatif untuk konversi biomassa menjadi bahan bakar cair yang cukup menjanjikan karena produk biofuel yang dihasilkan memiliki karakteristik identik dengan bahan bakar fosil. Biomassa dikonversi menjadi gas sintesis (CO dan $\mathrm{H}_{2}$ ) melalui polimerisasi menjadi hidrokarbon rantai panjang (wax) dan selanjutnya dipotong-potong melalui proses perengkahan menghasilkan hidrokarbon rantai pendek $\left(\mathrm{C}_{5}-\mathrm{C}_{12}\right)$ yang merupakan biofuel. Penggunaan karbon aktif sebagai penyangga dapat menghasilkan biofuel secara langsung. Penelitian ini bertujuan karakterisasi serbuk karbon aktif sebagai penyangga katalis logam yang akan digunakan dalam sintesis Fischer-Tropsch dan memanfaatkan limbah bambu sebagai sumber karbon aktif.. Pembuatan karbon aktif dari bambu ini dilakukan dengan kombinasi aktivasi Karbonisasi- $\mathrm{H}_{3} \mathrm{PO}_{4}(\mathrm{~A})$, Karbonisasi- $\mathrm{H}_{3} \mathrm{PO}_{4}$-Steam (B). Bambu dikecilkan ukurannya, dikeringkan dan diarangkan pada $500^{\circ} \mathrm{C}$ dengan aliran gas nitrogen dalam reaktor karbonisasi, diserbukkan, selanjutnya diaktivasi dengan $\mathrm{H}_{3} \mathrm{PO}_{4} 85 \%$ dan dicuci sampai $\mathrm{pH}$ netral. Setelah pengeringan, sampel difungsionalisasi dengan $\mathrm{HNO}_{3} 65 \%$, dinetralkan, dikeringkan dan dikalsinasi pada $700^{\circ} \mathrm{C}$. Struktur kristal pada karbon aktif dianalisa menggunakan XRD. Karbon aktif hasil berbagai urutan aktivasi memiliki profil XRD yang identik dan sudah menunjukkan spektra khas untuk karbon aktif. Karbon aktif yang dihasilkan sudah sesuai dengan struktur kristal berdasarkan sudut difraksi hasil analisis XRD. Aktivasi karbon yang diawali dengan steam kemudian ditreatment dengan asam fosfat $(B)$ menunjukkan hasil yang lebih baik dalam hal terbentuknya gugus fungsi oksigen. Spektra gugus fungsi alkohol, fenol, karbonil, karboksilat muncul dengan intensitas yang cukup besar dibandingkan perlakuan aktivasi tanpa menggunakan steam. Hal ini menunjukkan bahwa kombinasi aktivasi fisik (steam) dan aktivasi kimia (asam fosfat) meningkatkan terbentuknya gugus fungsi oksigen dibandingkan proses fungsionalisasi menggunakan asam nitrat saja.

Kata kunci: limbah bambu, serbuk karbon aktif, penyangga katalis 


\section{PENDAHULUAN}

Kebutuhan energi yang semakin tinggi berbanding terbalik dengan ketersediaan cadangan energi yang umumnya masih mengandalkan minyak bumi. Regulasi yang kurang baik menyebabkan harga minyak dunia semakin terpuruk di kisaran USD 50 perbarel. Hal ini menyebabkan konsumsi minyak bumi semakin meningkat dan mempercepat waktu habisnya cadangan energi fosil. Oleh karena itu, semakin banyak peneliti yang mencoba menggali potensi sumber energi baru dan terbarukan sebagai antisipasi permasalahan di atas. Sintesis Fischer-Tropsch merupakan teknologi untuk memproduksi bahan bakar yang memiliki karakteristik sama dengan bahan bakar fosil, sehingga dapat digunakan seutuhnya pada permesinan konvensional. Bahan baku teknologi ini adalah gas sintesis (campuran gas $\mathrm{CO}$ dan $\mathrm{H}_{2}$ ) yang dapat diperoleh dari batubara, gas alam maupun biomassa. Ada dua tahapan utama dalam konversi gas sintesis menjadi bahan bakar cair, yaitu reaksi polimerisasi (Fischer-Tropsch) dan perengkahan. Gas $\mathrm{CO}$ dipolimerisasi membentuk hidrokarbon rantai panjang yang selanjutnya dipotong-potong secara selektif dalam proses perengkahan menghasilkan hidrokarbon rantai pendek $\left(\mathrm{C}_{5}-\mathrm{C}_{12}\right)$ yang merupakan bahan bakar cair yang diinginkan. Katalis logam, seperti Co dan Fe banyak digunakan dalam reaksi Fischer-Tropsch, sedangkan zeolite HZSM-5 banyak digunakan dalam proses hydrocracking. Penggunaan dua tahapan proses ini cukup mahal, sehingga teknologi ini kurang layak secara komersial dan tidak banyak berkembang saat harga minyak dunia rendah. Sehingga diperlukan alternatif untuk menyederhanakan dua tahapan tersebut. Penggabungan katalis logam/zeolite [1] [2] [3] dan polimerisasi terbatas menggunakan logam/karbon [4], [5] sampai hidrokarbon rantai pendek dapat menyerhanakan proses menjadi satu tahap [6]. Konsep polimerisasi terbatas merupakan konsep baru yang akan dikaji dalam penelitian ini. Beberapa penelitian yang menggunakan karbon aktif sebagai penyangga katalis logam memberikan indikasi kenaikan selektivitas hidrokarbon rantai pendek (biofuel) dibandingkan penggunaan penyangga lain, namun selektivitas terhadap beberapa produk samping juga cukup tinggi. Katalis Co berpenyangga karbon aktif memberikan distribusi biofuel yang cukup tinggi dibandingkan penyangga karbon nanotube dan karbon mesopori [7]. Katalis $\mathrm{Fe}$ berpenyangga karbon aktif memberikan selektivitas biofuel cukup tinggi, namun selektivitas produk samping CO juga cukup tinggi [8]. Hal inilah yang akan diatasi dengan optimasi properti karbon aktif sehingga produk samping bisa ditekan seminimal mungkin dan selektivitas biofuel dapat ditingkatkan.

Salah satu sumber karbon aktif yang cukup potensial dan murah adalah limbah bambu, Karbon aktif yang diolah dari bambu menunjukkan karakteristik permukaan dan porositas yang baik [9]. Bambu dapat dikonversi menjadi arang dan karbon aktif melalui karbonisasi dilanjutkan aktivasi [10], [11]. Proses karbonisasi bertujuan untuk meningkatkan kandungan karbon dan 
menciptakan porositas awal, sedangkan proses aktivasi akan menambah jumlah pori. Karbonisasi dilakukan pada temperatur 300$400^{\circ} \mathrm{C}$. Proses karbonisasi akan menghasilkan gas dan minyak (tar) apabila didinginkan pada temperature kamar. Residu proses karbonisasi adalah arang primer yang merupakan material dasar dalam langkah aktivasi. Aktivasi steam pada temperatur lebih tinggi memberikan aktivasi yang lebih baik dan meningkatkan perluasan jaringan pori yang sempit [12]. Asma et al membuat karbon aktif dari limbah bambu menggunakan karbonisasi dan aktivasi steam dalam reaktor temperatur tinggi. Karbon aktif yang diperoleh dari bambu menunjukkan karakteristik permukaan dan porositas yang baik, dengan luas permukaan BET mencapai $719 \mathrm{~m}^{2} / \mathrm{g}$. Kondisi terbaik tercapai pada temperatur aktivasi $800^{\circ} \mathrm{C}$ dan waktu aktivasi 120 menit [9]. Hasil ini menunjukkan bahwa limbah bambu memiliki potensi yang cukup menjanjikan untuk produksi karbon aktif.

Material karbon bersifat inert, namun beberapa mengandung gugus fungsi yang melekat pada permukaannya. Gugus fungsi juga dapat dibuat sesuai keperluan dengan berbagai jenis agen fungsionalisasi. Gugus yang mengandung oksigen merupakan gugus fungsi yang paling banyak ditemukan pada permukaan karbon. Berbagai gugus fungsi mengandung oksigen seperti gugus karbonil, lakton, hidroksil, karbonil, kuinon, eter, piron, anhidrat karboksilat, kromin, laktol dan densitas electron $\pi$ pada karbon permukaan datar [13]. Berbagai metode digunakan untuk menambahkan gugus fungsi (fungsionalisasi) pada karbon aktif. Agen oksidasi yang dapat digunakan terdiri dari asam nitrat, hidrogen peroksida, kalium permanganat, asam sulfat dan natrium peroksidisulfida. Dari berbagai penelitian, oksidasi menggunakan oksidator kuat seperti asam nitrat atau natrium peroksidisulfat menghasilkan karbon dengan dominasi gugus karboksilat, sedangkan perlakuan dengan peroksida meningkatkan gugus fenol [15] [16]. Xiong et al. menggunakan logam $\mathrm{Fe}$ sebagai katalis dan melakukan fungsionalisasi pada 1 gram karbon bola (carbon sphere) menggunakan $100 \mathrm{~mL}$ asam nitrat (55\% volume) dengan hasil terbaik pada temperatur $90^{\circ} \mathrm{C}$ selama 17 jam (BET surface area 2,6 $\mathrm{m}^{2} / \mathrm{g}$ dan volume pori $0,0046 \mathrm{~cm}^{3} / \mathrm{g}$ ) [5]. Fu et al. menggunakan logam Co sebagai katalis dan melakukan fungsionalisasi pada karbon aktif menggunakan larutan asam nitrat $28 \%$ pada $80^{\circ} \mathrm{C}$ selama 4 jam (BET surface area 1897 $\mathrm{m}^{2} / \mathrm{g}$; volume pori $1,00 \mathrm{~cm}^{3} / \mathrm{g}$; ukuran pori 0,9 $\mathrm{nm}$ ) [7]. Karbon aktif memberikan karakteristik BET dan volume pori lebih baik dibandingkan karbon bola. Penelitian ini bertujuan untuk modifikasi properti karbon aktif yang dapat meningkatkan selektivitas biofuel dalam proses Fischer-Tropsch dan memanfaatkan limbah bambu sebagai sumber karbon aktif.

\section{METODOLOGI}

Bahan-bahan yang digunakan adalah bambu petung (Dendrocalamus asper), $\mathrm{H}_{3} \mathrm{PO}_{4}$ p.a. (Merck), $\mathrm{HNO}_{3}$ p.a. (Merck). Peralatan yang digunakan adalah reaktor karbonisasi (Gambar 1), hotplate magnetic 
stirrer, hot air oven, timbangan digital dan peralatan gelas standar.

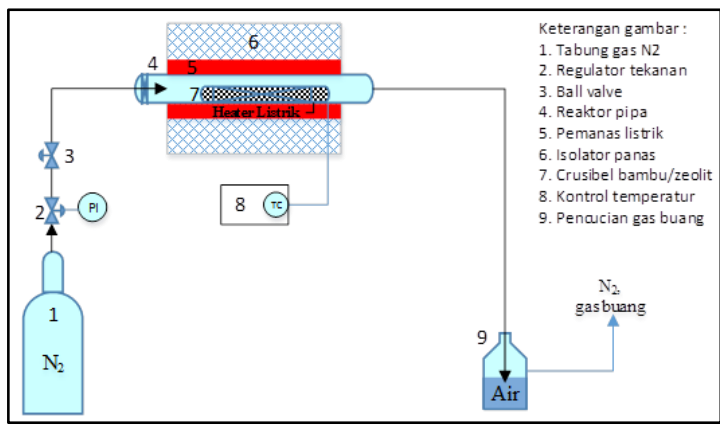

Gambar 1. Skema reaktor karbonisasi

Pembuatan karbon aktif dari bambu ini dilakukan dengan kombinasi aktivasi Karbonisasi- $\mathrm{H}_{3} \mathrm{PO}_{4}$ (A), Karbonisasi- $\mathrm{H}_{3} \mathrm{PO}_{4-}$ Steam (B). Bambu diserbukkan, dikeringkan dan diarangkan pada $500^{\circ} \mathrm{C}$ dengan aliran gas nitrogen dalam reaktor karbonisasi. Karboni-sasi dilakukan selama 2 jam. Arang bambu ditambah activating agent $\left(\mathrm{H}_{3} \mathrm{PO}_{4}\right)$ $85 \%$ dengan perbandingan bambu : $\mathrm{H}_{3} \mathrm{PO}_{4}$ sebesar 1:5 di aduk selama 1 jam pada suhu $85^{\circ} \mathrm{C}$, kemudian dilakukan pencucian sampai $\mathrm{pH}$ netral dan pengeringan di dalam oven pada suhu $\pm 110^{\circ} \mathrm{C}$ selama \pm 2 jam. Setelah pengeringan, sampel difungsionalisasi dengan $\mathrm{HNO}_{3} \quad 65 \%$. Tujuan utama fungsionalisasi adalah membentuk gugus fungsi oksigen yang akan memperkuat penambatan unsur logam $\mathrm{Fe}$ dan $\mathrm{Co}$ pada penyangga karbon pada impregnasi katalis. Setelah difungsionalisasi, dilakukan pencucian sampai $\mathrm{pH}$ netral dengan air distilasi untuk menghilangkan sisa-sisa activating agent. Setelah dicuci, sampel dikeringkan pada oven suhu $\pm 110^{\circ} \mathrm{C}$ selama 24 jam dan dikalsinasi selama 2 jam suhu $700^{\circ} \mathrm{C}$. Sampel karbon aktif yang didapatkan kemudian disimpan di dalam desikator untuk menjaga karbon aktif tetap kering. Karakterisasi karbon aktif dengan XRD, FTIR, BET dan Spektofometri.

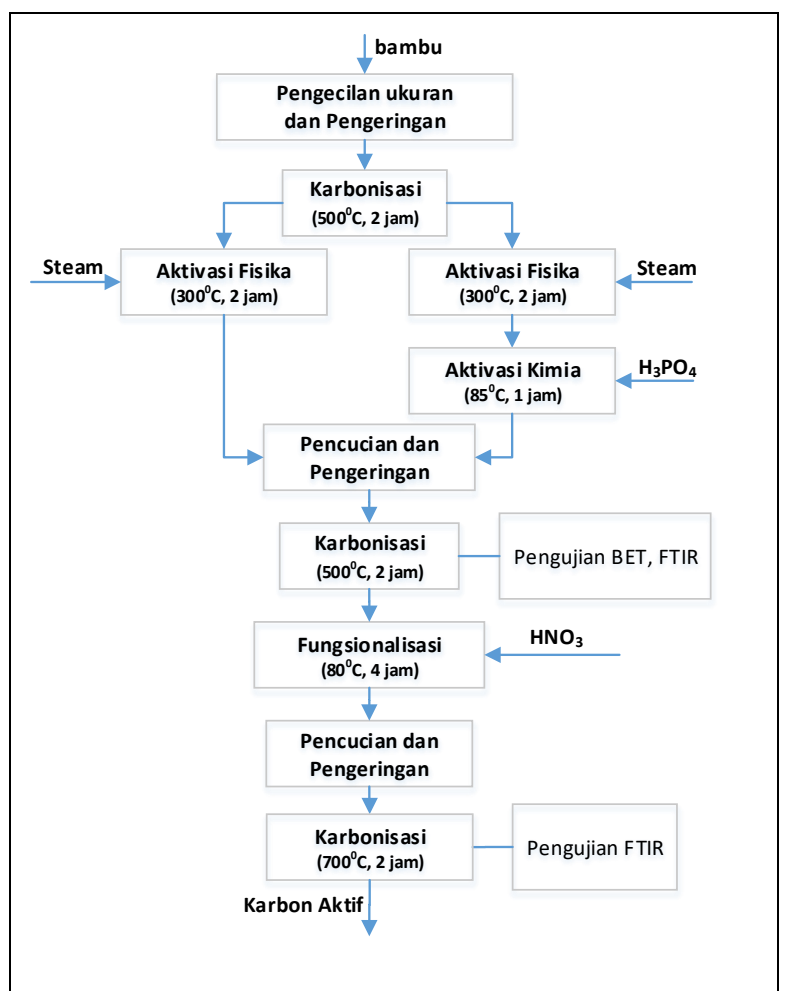

Gambar 2. Diagram alir penelitian

\section{HASIL DAN PEMBAHASAN}

\section{Pembuatan karbon aktif dari bambu}

Pembuatan karbon aktif menggunakan kombinasi aktivasi kimia dan fisika dengan variasi urutan aktivasi meliputi karbonisasi$\mathrm{H}_{3} \mathrm{PO}_{4} \quad(A)$, karbonisasi-steam- $\mathrm{H}_{3} \mathrm{PO}_{4} \quad$ (B). Luas permukaan, ukuran pori dan gugus fungsi merupakan parameter penting bagi karbon aktif yang akan digunakan sebagai penyangga katalis. Pengujian BET full isotherm pada karbon aktif hasil aktivasi $A$ menunjukkan luas permukaan hanya 5,700 $\mathrm{m}^{2} / \mathrm{g}$ dan diameter pori rata-rata sebesar 
2,6581 nm. Luas permukaan ini sangat kecil untuk karbon aktif. Kemungkinan hal ini disebabkan karena prosedur aktivasi yang tidak sesuai atau pemanasan pada reaktor kalsinasi yang kurang sempurna. Percobaan ini akan diulang kembali untuk memastikan kedua hal tersebut berjalan sebagaimana mestinya. Apabila ditinjau dari diameter pori, karbon aktif yang dihasilkan termasuk kategori mesopori. Hal ini sudah sesuai dengan spesifikasi yang diharapkan karena impregnasi katalis pada penyangga mesopori dapat meningkatkan difusivitas katalis sehingga kuantitas katalis yang masuk ke dalam pori lebih maksimal.

Struktur kristal pada karbon aktif dianalisa menggunakan XRD (X-Ray Diffraction). Untuk mengetahui struktur kristal pada puncak tertentu, dilakukan pencocokan dengan database dari berbagai jurnal. Profil karbon aktif pada analisis XRD dengan urutan aktivasi B ditunjukkan pada Gambar 3. Pola spektra XRD karbon aktif yang terbentuk identik dengan pola spektra XRD karbon aktif hasil penelitian Fu et al [7] seperti terlihat pada gambar 4. Puncak tajam terjadi pada sudut difraksi $2 \theta$ di bawah 100 dan puncak landai berada pada sudut difraksi $2 \theta$ antara 200 dan 250. Karbon aktif hasil berbagai urutan aktivasi memiliki profil XRD yang identik dan sudah menunjukkan spektra khas untuk karbon aktif.

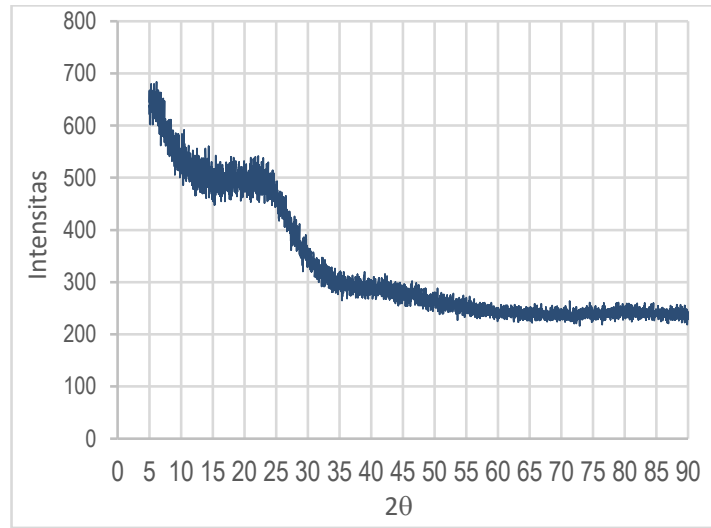

Gambar 3. Spektra XRD karbon aktif dengan urutan aktivasi karbonisasi-asam fosfat

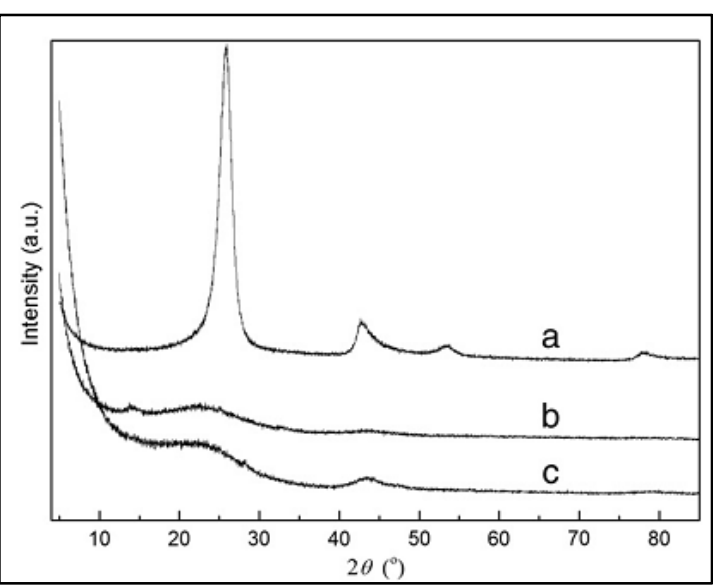

Gambar 4. Spektra XRD karbon aktif (kurva c) [7]

\section{Fungsionalisasi Karbon Aktif}

Fungsionalisasi karbon aktif merupakan proses pembentukan gugus fungsi pada permukaan karbon aktif yang bertujuan untuk meningkatkan kapasitas katalis logam yang dilekatkan pada permukaan karbon aktif saat impregnasi. Gugus fungsi oksigen banyak digunakan dalam proses fungsionalisasi karbon aktif sebagai katalis dalam reaksi Fischer-Tropsch. Keberadaan dan jenis gugus fungsi oksigen dalam karbon aktif yang dibuat dapat diuji menggunakan FTIR. Pengujian FTIR dilakukan pada karbon, 
urutan aktivasi A dan urutan aktivasi B dengan hasil ditunjukkan pada Gambar 5. Proses fungsionalisasi berhasil membentuk gugus oksigen berupa gugus karboksilat, karbonil, alkohol dan fenol. Besaran panjang gelombang dapat digunakan untuk menentukan untuk membandingkan kuantitas gugus fungsi yang terbentuk. Tabel 1. menunjukkan besaran panjang gelombang hasil pengujian FTIR untuk karbon, urutan aktivasi A dan B. Karbon yang belum diaktifkan sudah mengandung gugus fungsi fenol meskipun sangat minor yang ditunjukkan dengan puncak spektra yang kecil. Karbon yang diaktifkan melalui penambahan asam fosfat mengalami pelepasan gugus fungsi fenol dan asam karboksilat yang sudah ada sebelumnya sehingga hasil pengujian FTIR menunjukkan bahwa puncak spektra gugus fungsi tersebut mengalami penurunan. Aktivasi karbon yang diawali dengan steam kemudian ditreatment dengan asam fosfat (B) menunjukkan hasil yang lebih baik. Spektra gugus fungsi alkohol, fenol, karbonil, karboksilat muncul dengan intensitas yang cukup besar dibandingan perlakuan aktivasi tanpa menggunakan steam. Hal ini menunjukkan bahwa kombinasi aktivasi fisik (steam) dan aktivasi kimia (asam fosfat) meningkatkan terbentuknya gugus fungsi oksigen pada proses fungsionalisasi menggunakan asam nitrat. Aktivasi steam melakukan penetrasi air pada pori serbuk karbon sehingga meningkatkan sifat hidrofilik karbon. Sifat hidrofilik ini membantu meningkatkan aktivitas asam fosfat dalam proses aktivasi maupun meningkatkan kinerja asam nitrat dalam proses fungsionalisasi.

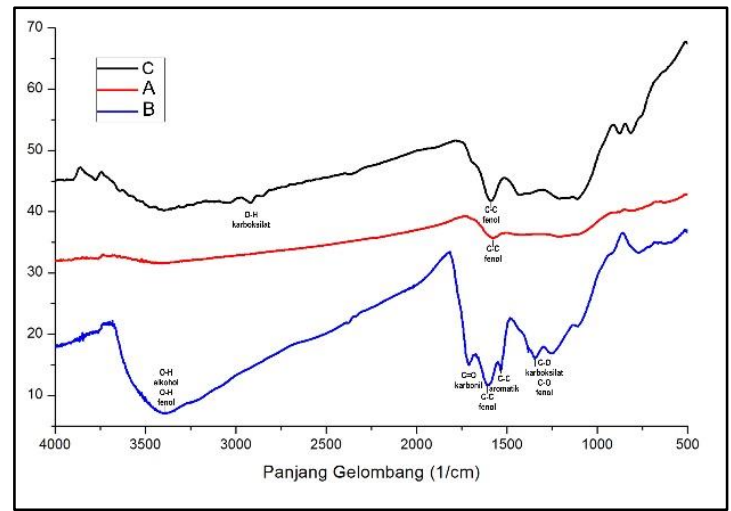

Gambar 5. Spektra FTIR karbon dan karbon aktif terfungsionalisasi pada urutan aktivasi $A$ dan $B$

Tabel 1. Gugus fungsi yang terbentuk setelah proses fungsionalisasi

\begin{tabular}{|c|c|c|c|c|}
\hline Urutan Aktivasi & peak $(1 / \mathrm{cm})$ & Area & Gugus Fungsi (primer) & Gugus Fungsi (sekunder) \\
\hline \multirow{7}{*}{ Karbon } & 1111.03 & 110.832 & C-O karboksilat & \\
\hline & 1209.41 & 64.499 & C-O karboksilat & \\
\hline & 1429.3 & 67.793 & C-C aromatik & \\
\hline & 1587.47 & 137.291 & C-C aromatik & \\
\hline & 2858.6 & 27.766 & $\mathrm{O}-\mathrm{H}$ karboksilat & C-H alkana \\
\hline & 2916.47 & 22.993 & O-H karboksilat & C-H alkana \\
\hline & 3381.33 & 12.641 & O-H alkohol & $\mathrm{O}-\mathrm{H}$ fenol \\
\hline \multirow{5}{*}{ P1 fungsi } & 1109.11 & 89.004 & C-O karboksilat & \\
\hline & 1209.41 & 42.732 & C-O karboksilat & \\
\hline & 1413.87 & 8.507 & C-C aromatik & \\
\hline & 1572.04 & 8.612 & C-C aromatik & \\
\hline & 3398.69 & 9.648 & O-H alkohol & $\mathrm{O}-\mathrm{H}$ fenol \\
\hline \multirow{7}{*}{ P2 fungsi } & 1111.03 & 95.137 & C-O karboksilat & \\
\hline & 1253.77 & 58.915 & C-O karboksilat & \\
\hline & 1344.43 & 38.235 & $\mathrm{~N}-\mathrm{O}$ senyawa nitro & \\
\hline & 1535.39 & 20.48 & C-C aromatik & \\
\hline & 1606.76 & 29.501 & C-C aromatik & C-C alkena \\
\hline & 1708.99 & 56.284 & $\mathrm{C}=\mathrm{O}$ karbonil & \\
\hline & 3387.11 & 5.054 & $\mathrm{O}-\mathrm{H}$ alkohol & $\mathrm{O}-\mathrm{H}$ fenol \\
\hline
\end{tabular}

\section{KESIMPULAN}

Karbon aktif hasil berbagai urutan aktivasi memiliki profil XRD yang identik dan sudah menunjukkan spektra khas untuk karbon aktif. Karbon aktif yang dihasilkan sudah sesuai dengan struktur kristal berdasarkan sudut difraksi hasil analisis XRD. Aktivasi karbon yang diawali dengan steam kemudian ditreatment dengan asam fosfat (B) menunjukkan hasil yang lebih baik dalam hal terbentuknya gugus fungsi oksigen. Spektra gugus fungsi alkohol, fenol, karbonil, 
karboksilat muncul dengan intensitas yang cukup besar dibandingkan perlakuan aktivasi tanpa menggunakan steam. Hal ini menunjukkan bahwa kombinasi aktivasi fisik (steam) dan aktivasi kimia (asam fosfat) meningkatkan terbentuknya gugus fungsi oksigen dibandingkan proses fungsionalisasi menggunakan asam nitrat saja.

\section{DAFTAR PUSTAKA}

[1] S. Bessell, "Investigation of bifunctional zeolite supported cobalt Fischer-Tropsch catalysts," Appl. Catal. A, Gen., vol. 126, no. 2, pp. 235-244, 1995.

[2] A. N. Pour, M. Zare, S. M. Kamali Shahri, Y. Zamani, and M. R. Alaei, "Catalytic Behaviors of Bifunctional Fe-HZSM-5 Catalyst in FischerTropsch Synthesis," J. Nat. Gas Sci. Eng., vol. 1, no. 6, pp. 183-189, 2009.

[3] M. J. Valero-Romero et al., "Carbon/H-ZSM-5 Composites as Supports for Bi-Functional FischerTropsch Synthesis Catalysts," Catal. Sci. Technol., vol. 6, no. 8, pp. 2633-2646, 2016.

[4] T. Fu, Y. Jiang, J. Lv, and Z. Li, "Effect of Carbon Support on Fischer-Tropsch Synthesis Activity and Product Distribution over Co-Based Catalysts," Fuel Process. Technol., vol. 110, pp. 141-149, 2013.

[5] H. Xiong, M. Moyo, M. A. M. Motchelaho, L. L. Jewell, and N. J. Coville, "Applied Catalysis A General Fischer - Tropsch Synthesis over Model Iron Catalysts Supported on Carbon Spheres: The effect of Iron Precursor, Support Pretreatment, Catalyst Preparation Method and Promoters," "Applied Catal. A, Gen., vol. 388, no. 1-2, pp. 168178, 2010.
[6] L. V Sineva, E. Y. Asalieva, and V. Z. Mordkovich, "The Role of Zeolite in The Fischer-Tropsch Synthesis over Cobalt-Zeolite Catalysts," Russ. Chem. Rev., vol. 84, no. 11, pp. 1176-1189, 2015.

[7] T. Fu, Y. Jiang, J. Lv, and Z. Li, "Effect of carbon support on Fischer - Tropsch synthesis activity and product distribution over Co-based catalysts," Fuel Process. Technol., vol. 110, pp. 141-149, 2013.

[8] W. Ma, Y. Ding, J. Yang, X. Liu, and L. Lin, "Study of Activated Carbon Supported Iron Catalysts for Teh Fischer-Tropsch Synthesis," vol. 84, no. 1, pp. 11-19, 2005.

[9] I. W. Asma, J. Rafidah, E. Puad, and H. Shaharuddin, "Production of Activated Carbon from Industrial Bamboo Wastes," vol. 23, no. 4, pp. 417424, 2011.

[10] B. H. Hameed, A. T. M. Din, and A. L. Ahmad, "Adsorption of methylene blue onto bamboo-based activated carbon: Kinetics and equilibrium studies," J. Hazard. Mater., vol. 141, no. 3, pp. 819-825, 2007.

[11] E. L. K. Mui, W. H. Cheung, M. Valix, and G. Mckay, "Activated carbons from bamboo scaffolding using acid activation," Sep. Purif. Technol., vol. 74, no. 2, pp. 213-218, 2010.

[12] B. G. Prakash Kumar, K. Shivakamy, L. R. Miranda, and M. Velan, "Preparation of steam activated carbon from rubberwood sawdust (Hevea brasiliensis) and its adsorption kinetics," J. Hazard. Mater., vol. 136, no. 3, pp. 922-929, 2006.

[13] J. L. Figueiredo and P. Serp, Carbon Material for Catalysis. Hobokem New Jersey: John Wiley \& Sons, Inc, 2009.

[14] J. A. Bandosz, T. J.; Jagielo, J.; Amankwah, K. A. G.; Schwardz, "Chemical and Structural Properties of Clay Minerals Modified by Inorganic and Organic Material," Clay Miner., vol. 27, no. 4, pp. 435-444, 1992.

[15] I. I. Salame and T. J. Bandosz, "Surface Chemistry of Activated Carbons: Combining the Results of Temperature-Programmed Desorption, Boehm, and Potentiometric Titrations.," J. Colloid Interface Sci., vol. 240, no. 1, pp. 252-258, 2001. 